\title{
Online Motor Vehicle Licensing System Using RBAC Mechanism
}

\author{
EL-HASSAN Sherifat. O $^{1}$, EBELOGU Christopher $\mathbf{U}^{2}$, HAMMAWA Mohammed. $\mathrm{B}^{3}$, BISALLAH Hashim. $\mathrm{I}^{4}$ \\ Research Scholar ${ }^{1-2}$ and Lecturer ${ }^{3-4}$ \\ Department of Computer Science, \\ University of Abuja, Abuja,
}

Nigeria

\begin{abstract}
Motor vehicle administration is a composite process and revolves around the management and the control of motor licensing. Motor vehicle licensing is the payment of a fee for the use of motor vehicles on public roads. Motor vehicle licensing in Nigeria began over 100 years ago starting from the colonial administration and the records then were manually kept which did not help in raising the efficiency of the general automotive services. The current process of motor vehicle licensing is being operated manually and due to this procedure, numerous problems are been encountered. This study seeks to develop a software that links all the procedures of the motor vehicle licensing system in motor license authority in the manual system of motor vehicle registration and introduces a better system which is the computerized system that will contribute to providing solutions to the problems in the manual system. This work was designed to aid the framework for a client-server distributed database system for licensing and registration of automobiles in Nigeria online. The system was implemented using PHP scripting language, HTML, MySQL Server, and Macromedia Dreamweaver. This study highly recommends that the motor vehicle licensing office should set up a computer-based system and more research done to perfect and make it more useful.
\end{abstract}

Key Words: Vehicle Inspection Office (VIO), Vehicle Registration, Vehicle Licensing, Vehicle Registration and Enquiry Software (VehRES) System, Licensing office, Federal Road Safety Commission (FRSC), Role-based access control (RBAC) Mechanism.

\section{INTRODUCTION}

In recent times, there has been growing need to computerize the operations of big establishments, both public and private, to increase their overall efficiency. This is achieved by using computer to store, process, and retrieve information as well as generates report. These computers make use of application packages, which is a computer program and manuals designed to cover all aspects of particular task in realizing the objective. It is now widely accepted that the coordination of all complex functions of an organization is greatly assisted by en efficient data processing system.

In Nigeria, three arms of government agencies are responsible for automobile licensing, registration and control. They are Federal Road Safety Commission (FRSC), the state Vehicle Inspection Office (VIO), and the state Board of Internal Revenue (BIR). The usual practice is for an owner to visit these three arms for the necessary payment, data collection and issuance of necessary documents and materials such as plate numbers. The state board of internal revenue collects fees for new automobile licenses and registration from owners through a designated bank. They may request more documents such as custom papers, purchase receipt, or a change of owner certificate on automobile [1].

Every automobile within Nigeria must be registered under a state and a local government before a license plate is issued. Nigerian automobile registration plates often have the state written at the top and have a group of three letters at the right hand side, indicating the district of registration followed by their main town to aid in tracing and identifying location. License plates help law enforcement, motor vehicle authorities and others identify a vehicle while simultaneously indicating that the registrant has paid the proper registration fee and taxes on the automobile. License plates also offer information such as the weight class, the country, state and local government in which the vehicle is registered, use restrictions (private or commercial), and the age and engine capacity. In addition, some license plates show whether the owner of the vehicle is a member of special organization or group 
such as the police force, custom and the federal road safety commission. Moreover, proof of ownership certificates are issued by the board to owners of automobiles on payment of certain fee [2].

Apart from other advantages, the computerized motor vehicle licensing system will replace the manual process of registering vehicle, issuing licenses, renewing expired licenses, as well changing of ownership of the vehicle. Since the computerize mode of operation is flexible and accurate record keeping assured, it will give the management of the motor licensing authority enough time for planning and decision making rather than being immersed in the detail of routine function (manual work).

This is necessary since the control of any establishment ultimately lies in the hand of management. Also, the computerized operations of the licensing authority will ensure a very fast retrieval of necessary information about a vehicle (e.g.) vehicle information to the police in terms of urgent need like during that of road accident.

In computerization and implementation of motor vehicle licensing system, all the three level organization; vehicle inspection office, (VIO), Federal Road Safety Commission (FRSC), and the Board of Internal revenue, which are required to monitor the processes that are involved starting from the exact date of motor vehicle is registered, licensed, renewed, etc can be created in such a way that the three can interact and a relationship can be formed within them.

Online Motor vehicle licensing system is a phenomenon that is still estranged to the Nigerian terrains, although many western countries, e.g., United States of America, and some Asian countries have implemented online licensing in one form or the other; it is yet to gain popularity in this part of the world. The obvious merits of online motor vehicle licensing system prompted this research project to see ways of integrating our vehicle licensing to the internet for speed, efficiency, reliability, and customer satisfaction.

In a highly populated country such as Nigeria, where the number of car owners increases yearly, the registration of motor vehicle is a slow process and sometimes in the sense of it a difficult task. This is true in the sense that motor vehicle licensing authority/ system attend to millions of cars per year; thus keeping records of license and their registrations manually was a tedious work. It resulted in files containing records of application being misplaced, damaged or misfiled due to the way the manual method of writing these records. Also writing records of applicants in books affected the span of the record materials, and since the continue use and re-use of these booklets everyday might lead to wear and tear which may eventually led to loss of important information [3].

\subsection{Problem Statement}

Below are some of the problems that are being encountered in the manual system of assigning a plate number to newly acquired vehicle in the department of vehicle licensing and registration.

(i) Participation of Unauthorized Officers: Unauthorized officers according to my observation are involved in the vehicle registration especially in the registration of illegal vehicles which can encourage fraud.

(ii) Wrong Charging of Fees: The officer in-charge may charge a wrong bill to vehicle owners, which may be as a result of underassessment or over assessment of vehicles. This could be with motive to commit fraud or as a result of mistake on the part of the officer.

(iii) Wrong Sales Allocation: Staff under a particular state motor vehicle licensing office indulges in registering of vehicles that does not belong to their state.

(iv) Improper Accounting: There is the tendency of the cashier involved in the handling of income generated to make mistake during this process, thus having some measures of inaccuracy in the work.

(v) There is difficulty, at times, in tracing a record/information or cautioning a vehicle owner due to improper information keeping as a result of carelessness or volume in the size of record kept.

(vi) Mental/Manual Labor: This involves the use of strength and brain and the body. The officer-in-charge goes through mental labour because he has to sort the records of the entire vehicle in his domain of jurisdiction. He suffers from manual labour because he has to manually write all the records.

(vii) Excess Time Consumption: There is excessive time consumption because the motor licensing officer has to write and enter the information of the vehicle after the person whose vehicle is to be registered has paid a prescribed amount of money to the licensing authority accompanied with duly completed application, depending on the type of vehicle, write personal information about the person whose vehicle is to be registered and the category of vehicle whether commercial, privates, special purpose and 
so on, then the plate number and vehicle license is prepared after a given period of time. When put together, the time spent on all of these is much.

\subsection{Aims and Objectives}

The aim is to develop a software that links all the procedures of motor vehicle licensing system in motor license authority in on the current online motor vehicle registration system and introduces a better system which is the computerized system with access control based on roles in the organization and implemented using RBAC mechanisms which will contribute in providing solutions to the problems in the current system.

- To improve the system performance and efficiency.

- To ensure a very high level of accuracy during registration of a vehicle or category of vehicles that are prone to errors.

- To enhance the database for proper information and record keeping.

- To reduce fraudulent activities by unauthorized staffs.

- To provide a reliable security access in order to avoid tempering with stored data.

- To provide a means of accessibility in case of accident and emergency.

- To enhance speedy recovery of stolen vehicles

- To make the current online system of registration highly organized and work based on the organization of the vehicle licensing organization.

\section{LITERATURE REVIEW}

\subsection{Conceptual framework}

\subsubsection{Concept of vehicle licensing}

A vehicle license (also called a vehicle registration certificate in some jurisdictions) is issued by a motor registration authority in a jurisdiction in respect of a particular motor vehicle. A current license is required for a motor vehicle to be legally permitted to be used or kept on a public road in the jurisdiction. Usually, a license is valid for one year and an annual license fee is payable before a new one is issued (revalidation).

A vehicle license may be a paper document to be kept in the vehicle at all times or in the form of an adhesive sticker to be affixed or displayed on the windshield of the vehicle or on the registration plate. The rules of vehicle licensing are in addition to those of vehicle registration, roadworthiness certification and insurance and other requirements.

Many jurisdictions have ceased issuing or requiring display of registration certificates and have instead adopted number plate recognition systems.

\subsubsection{History of motor licensing}

Nigerian vehicle registration in current use was introduced in 1992 and revised in 2011. Nigeria and Liberia are the only two African countries that use the North American standard $6 \times 12$ inches $(152 \times 300 \mathrm{~mm})$. The international code for Nigeria is "WAN" (West Africa Nigeria).

In the early $80 \mathrm{~s}$, the vehicle licensing system then was that each vehicle was licensed based on the local government issuing the licenses. For instance, a vehicle licensed from Ikorodu could bear (LAG 28 IKD) as plate number. Later with the formation of the Federal Road Safety Commission (FRSC) in February 18, 1988, many procedures were changed, the plate number format and their various slogans. Also, it was made constitutional under the motor vehicle administration as a Residual issue under the 1999 Nigerian constitution that a person seeking for vehicle licensing must first possess the National driving license but currently not enforced.

Motor vehicle administration is a composite process and revolves around the management and the control of motor licensing including driving and other related licenses operations which include the following matters:

1. Issuance and renewal of:

- Motor vehicle licenses

- Driving license

- Learners permit

- Certificate of Roadworthiness of all licenses issued

2. Registration of vehicle

3. Preparing and keeping of statutory Registers of all licenses issued. 
4. Collection of fees emanating from its operation and payment of same into the appropriate subhead of the state government's account.

The license plates are generally white and the number itself is imprinted in blue. In the upper left-hand corner they carry the Flag of Nigeria or the national coat of arms. The state name and slogan is displayed at the top centre of the plate, and the "Federal Republic of Nigeria" is written at the bottom.

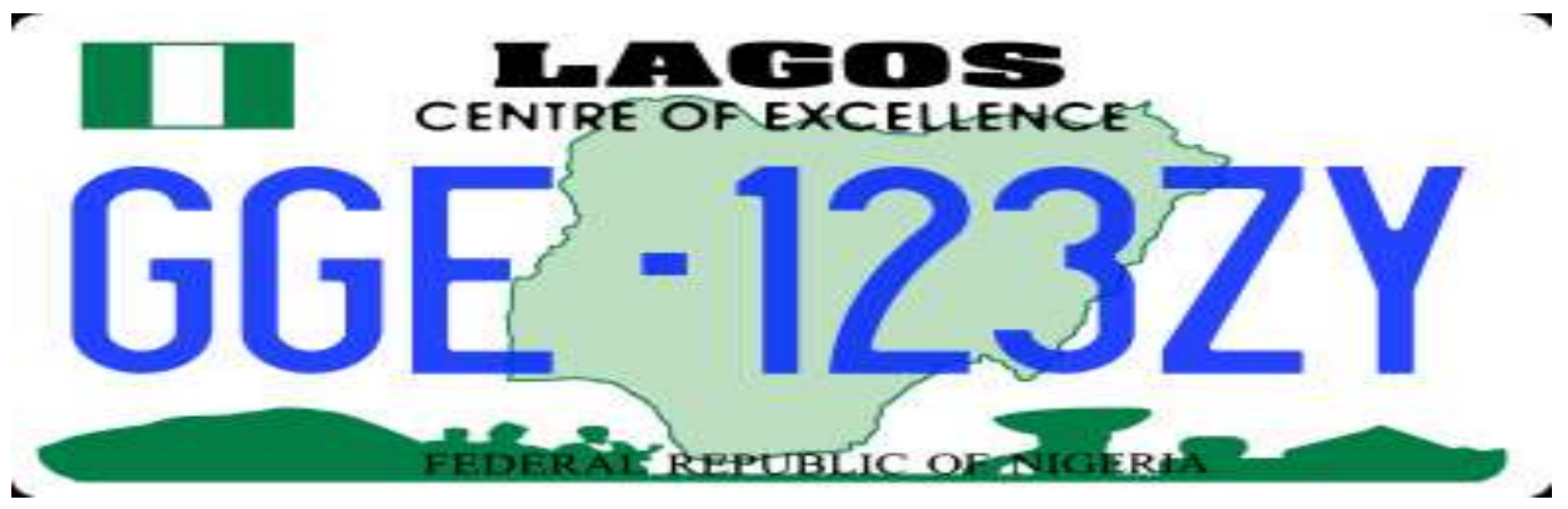

Figure 2.1 Vehicle license plate of Nigeria

The unique plate combination itself is in the format ABC-123DE. The first three letters indicate the Local Government Area in which the vehicle was registered, which are followed by three digits and two letters. The background consists of an outline of a map of Nigeria. Before 2011, the three letters indicating the Local Government Area were at the end, in the format AB123-CDE.

Other types of license plates are also in use. Commercial vehicles are written in red rather than blue, and government plates are in green. Diplomatic plates are purple and green with white lettering. The first two/three digits represent the country the owner of the car represents, followed by two letters and numbers. Instead of the name of the state, they read CORPS DIPLOMATIQUE. Cars of the consular corps have instead the letters CC or CORPS CONSULAIRE.

The trend of urbanization and city growth in developing countries are characterized by rapidity of urban increase, urbanization outpacing industrialization, and a high rate of urban population growth by natural increase and migration [4]. In Nigeria, urbanization has a fairly long history in its growth and development. Historical account [5] shows that extensive urban development in Nigeria predates the British colonial administration. Early explorers, missionaries and merchants estimates of population of towns show the existence of substantial human settlements in this part of the world in the 19th century. During this period, the major factors crucial to the growth and development of cities were trading, marketing and administration.

The second half of the 20th century witnessed rapid rate of urbanization and emergence of cities in various parts of Nigeria due to a number of factors among which are: introduction of wheeled transportation, particularly railway and road; categorization of settlement into hierarchical order of township; introduction of monetized economy and consequently production of cash crops and exploitation of mineral resources; continuous geopolitical restructuring, through creation of states and local governments (in 1967, 1976, 1987, 1991 and 1996), and the industrialization process between 1960 and 1975, which was based on import substitution strategies and consumer market for imported goods and services [4].

In many Nigerian cities, urban transport exhibits remarkable features. Several studies have revealed these features of Nigerian urban transport. Among these features as summarized by [4] are:

(a) Urban Transport System in the Nigerian cities are characterized by $95 \%$ of urban trips are by road. Out of this, about $70 \%$ of the urban trips are made by public transport. Inter modality of trips is limited to public transport journey by road based public transport.

(b) Ownership and organization of road public transport systems are characterized by haphazard and uncoordinated operators and complete absence of comprehensive and integrated of urban mass transit public transportation system. Specifically poor condition of city roads which in turns shortens lifespan of motor vehicles and high cost of maintenance.

It noted that the country has the lowest level of motorization in West Africa with as low as 4 vehicles per 1000 inhabitants. To compound the problem further, the rate of vehicle growth is much lower than the population growth rate. Resulting from this mismatch is a general fall in the level of motorization in all parts of the country. Since 1982 and up till 1989/1990 there was a substantial reduction in new vehicle registration in all parts of the country. Nigeria's Motor Vehicle Registered was reported at 3,750.000 Unit in Dec 2015. This records an increase from the previous number of 3,590.000 Unit for Dec 2014. Nigeria's Motor Vehicle Registered data is updated yearly, averaging 3,090.000 Unit from Dec 2005 to 2015, with 11 observations. The data reached an all-time high of 3,750.000 Unit in 2015 and a record low of 1,747.000 Unit in 2005. 
Government data was reported at 149,469.538 Unit in June 2018. This records an increase from the previous number of 139,263.538 Unit for Mar 2018. Nigeria's Number of Registered Vehicles: Government data is updated quarterly, averaging 139,012.038 Unit from Sep 2017 to Jun 2018, with 4 observations. The data reached an all-time high of 149,469.538 Unit in Jun 2018 and a record low of 135,215.538 Unit in Sep 2017 [6].

\subsection{Theoretical review}

\subsubsection{Theoretical review on vehicle licensing system}

According to [1], "our vehicle registration offices today are faced with potential rise and inefficiencies associated with manual i.e. paper based processes which are costly, prone to error and require mental and manual labor. Heightened regulation in the country is also placing these vehicle owners under pressure to meet litigation needs".

According to [7], "the level of tediousness the manual system of vehicle registration is so alarming that requires a new modified method that will be easy and simple."

According to [8], "most vehicle owner finds it difficult to register their vehicle on time due to the manual process which consumes time. For you to register your vehicle within a short period, you need to know one or two persons in the licensing office. This factor is peculiar to most Nigerian offices".

\subsubsection{Theoretical review on the use of RBAC mechanism to enhance security of system services}

[9] analyzes and compares the requirements and challenges in internet systems environments, both centralized and distributed. On the other hand, [10] summarizes the existing contributions regarding security in internet system services. One of the main conclusions after analyzing these works is the necessity of providing scalable and flexible security models for this kind of system, where the special constraints of the devices make traditional mechanisms not directly applicable.

If we look back, security management of large systems has been traditionally simplified by a Role-Based Access Control approach (RBAC), a policy mechanism defined around roles and privileges. This approach scales better than other previous models like Identity-Based Access Control (IBAC), based on the authenticated identity of an individual [11].

However, when talking about a huge amount of devices, managing roles for individual entities presents a big challenge. As we will analyze later, the possibility of grouping sensors and assigning roles to those that have the same rights is a good solution for this problem. On the other hand, by treating roles and identity as characteristics of a principal, Attribute-Based Access Control (ABAC), a paradigm whereby access rights are granted to users through the use of policies that combine attributes together, fully encompasses the functionality of both IBAC and RBAC and allows the definition of permissions based on just about any relevant security characteristic [12].

An ABAC model solves the issue of managing a big number of rules by generating dynamic access policies, and the challenge it presents is the huge number of attributes that need to be managed.

It was asserted that a compact policy can reduce the size of private keys [13]. They demonstrate how to provide access policies to facilitate more flexible access control for data access services on clouds. However, performing the token validation in the device implies an extra computational load that is better to avoid. Other approaches have used ABAC models, combined in some cases with the second version of the OAuth protocol (OAuth 2.0) or the Constrained Application Protocol (CoAP), to protect access to the data.

Four key roles was defined by [14] to explain the actors and the flow to get a protected resource. The resource owner is the entity capable of granting access to the resource. For its part, the resource server is where the protected resources are hosted, and it is capable of accepting and responding to protected resource requests using access tokens (a string that represents the user in terms of authorization). The client is the application making requests, and finally, the authorization server issues access tokens to the client after successfully authenticating the resource owner and obtaining authorization.

Thinking in terms of common internet system service environments such us smart cities or homes, we can observe that there are many types of devices that provide and consume data in the deployed services and applications. Moreover, a device can use multiple services at the same time having different access grants for each of them. Thus, using an RBAC/ABAC approach to manage authorization is a good decision. On the other hand, the use of OAuth 2.0 protocol to create access tokens that represent the devices delegates the authentication to an external service and saves load in the devices. We adopt both ideas for designing the solution we propose.

However, all the approaches exposed above consider the device as the object of the operations. The other entity (a client or an external service) is the subject that sends a request to the device in order to perform an action (in the case of actuators) or to get information (in the case of sensors). If we change this paradigm by making the device the subject that checks or updates information in a publish/subscribe service, we can manage authorization and authentication externally. 


\subsection{The need for technologies and commercial software for collecting vehicle registration data}

A variety of technologies have been tested and used by many law enforcement agencies in Nigeria. The technologies used in data collection and processing include a variety of systems such as optical scanners, Mobile Phones, printers, optical storage disks, portable computers, and digital cameras.

The current computer technologies allow vehicle owners to pay their registration/renewal bills at the designated banks or existing offices, electronically transfer the payment to the state agency account and provide deposit slips for the collection of receipts at the state agencies. The use of on - line error checks, and subsequently the needs for reentering Vehicle detailed data are not inevitable. At the beginning, these devices seem to be the best solution to all the registration problems because it tackles the issues of payment of vehicles registration dues into the government's accounts.

However, it still has its limitation, as they have not met up with the demands of the masses that spend endless time anxiously waiting for their demands to be met at the Licensing/Commission offices. Hence, the full computerization has not been effected as expected while technology and software programming has advanced in other countries. Many questions beg for answers: Shall we continue to wait for the criminals to get away with our stolen vehicles? Shall we keep spending endless time waiting on queues in offices full of corrupt practices of officials based on personalities? Shall we spend endless time searching for owners of whose vehicles have been recovered when software can be developed to tackle such problem like these?

The merit of automation is far reaching more than just saving time and cost; automating gives motor vehicle licensing the means to truly streamline the vehicle registration processes. Automating manual processing tasks let registration officers eliminate duplicate data entry, move towards a completely paperless environment and process multi-day function. Emphasizing the use of technology in vehicle registration, [15], stated that "in developing computerized system which can help motor licensing officers and offices to automatically register with ease, so that the process becomes an automatic day-to-day operation". The computerbased motor vehicle licensing solution can help motor licensing officers and offices to:

- Improve registration: By automating the manual based processes, errors caused by manual interventions can be reduced and electronic process support enables faster processing time.

- Meet regulatory demands: Archive, email and documentation so that it is easily accessible, usable and quickly retrievable for legal demands.

- $\quad$ Reduce costs: By reducing the administrative burden of paper management and error prone and repetitive data entry.

\section{SYSTEM METHODOLOGY, ANALYSIS, DESIGN AND IMPLEMENTATION}

\subsection{Existing and proposed system}

\subsubsection{Analysis of Existing system}

The sequence of manual mode of the Vehicle Licensing Authority involves the following four major operational areas:

Registration of Vehicles: cars can be registered for two main reasons:

- For Record Purposes in the case of Loss

- For Easy Identification

Registrations of cars are in two ways, one is for those manufactured or assembled and bought here in the country, and the other is for those imported into the country. For those bought into the country the owner will produce the following documents: custom duty certificate, bill of entry, bill of lading, custom payment schedule, import duty certificate, receipt authenticating the total amount paid to the former owner be it government or the vehicle dealer together with the host of other document. Other methods of data collection used were through recording sources, such as manuals, magazines, books etc.

Through the interview, and with the application forms normally issued to prospective customers for completion. The data collected were analyzed and prepared to make sure that all the vital information required for any customer's record were properly fed into the computer for necessary computation and report generated.

After going through this, the inspecting officer in writing on the completed form for the applicant to go ahead with registration of his vehicle as well state the fees to be paid for the vehicle.

The fees are charged based on the following:

- The category of the vehicle

- The amount the vehicle is bought

- The purpose the vehicle will serve 
These fees are summarized below:

N500.00 (Motorcycle)

N1, 000.00 (Motor vehicle bought below one million naira)

N20, 000.00 (Commercial vehicle bought up to one million naira)

$\mathrm{N} 3,000.00$ (private vehicle bought up to one million naira)

The following then is provided for inspection of the vehicle:
a. Completed application form issued by the authority
b. Receipts of purchase of vehicle from the manufacturer
c. Physical presence of the vehicle for inspection by the authority
d. Receipt of fees charged for registration

The essence of the inspection is to ensure that information supplied in the application form by the owner such as the chassis number tally with what is on the vehicle and for the vehicles imported into the country.

When the office is satisfied with all these requirements, the vehicle will then be registered.

\section{Issuance of Driving License}

Licenses are imposed taxes by the government to maintain roads the vehicles ply. They give permission to the owners holding the license to drive a vehicle. The license is the authority given to the owner and it ensures that the is capable of driving the vehicle covered by the license. The joint tax board fixes the fees charged for the license, a Federal Government Board responsible for imposition of taxes in the country and membership comprises all chairman of State Board of Internal Revenues.

\section{To obtain a driving License, the applicant must:}

1. Hold a learner's permit (obtained from the authority) for a minimum of six months, authorizing him or her to drive

2. Participate in a driving test conducted by the authority

3. On successful completion, he/she will be made to do direct capture for passport sized photographs

4. Then will be directed to pay a fee of any of the convenient cost

- Cost of 3-year driver’s license: $¥ 6,350$

- Cost of 5-year driver’s license: $\$ 10,450$

The different categories of driving license issued include

- Private "A" for Motorcycles

- $\quad$ Private " $\mathrm{B}$ " for private cars

- Professional "E" for any vehicle below and including mini buses

- Class "E" higher Buses above mini buses

\section{Renewal of License}

- For the first issuance of a license, the duration is five years and the subsequent ones last for two years. For renewal, another direct capture of photographs is needed. We note that any driving license issued by any licensing office in the country can be renewed in any other licensing office in the country since they play the same role. The renewal fee for expired drivers license: $\$ 6,350$ for a 3-year license, Provisional driving licence cost/ Learners permit: $¥ 50$ and Riders card: $\$ 800$ 


\section{Change of Ownership}

Changing the ownership of a vehicle arises when the former owner of the vehicle decides to sell the car to another person. For the new owner of the vehicle to operate it under the law, the licensing authority will effect change of ownership with the following documents produced by the new owner
* Original registration certificate of previous owner.
* Authority from the previous owner for change of ownership
* Receipt of purchase from the previous owner

We can conclude that the existing system is also: Monotonous to its operation, Inaccurate, Inconsistent, Unreliable, and Unproductive, Substandard etc. Having considered all these, it becomes obvious that a new computerized system is needed.

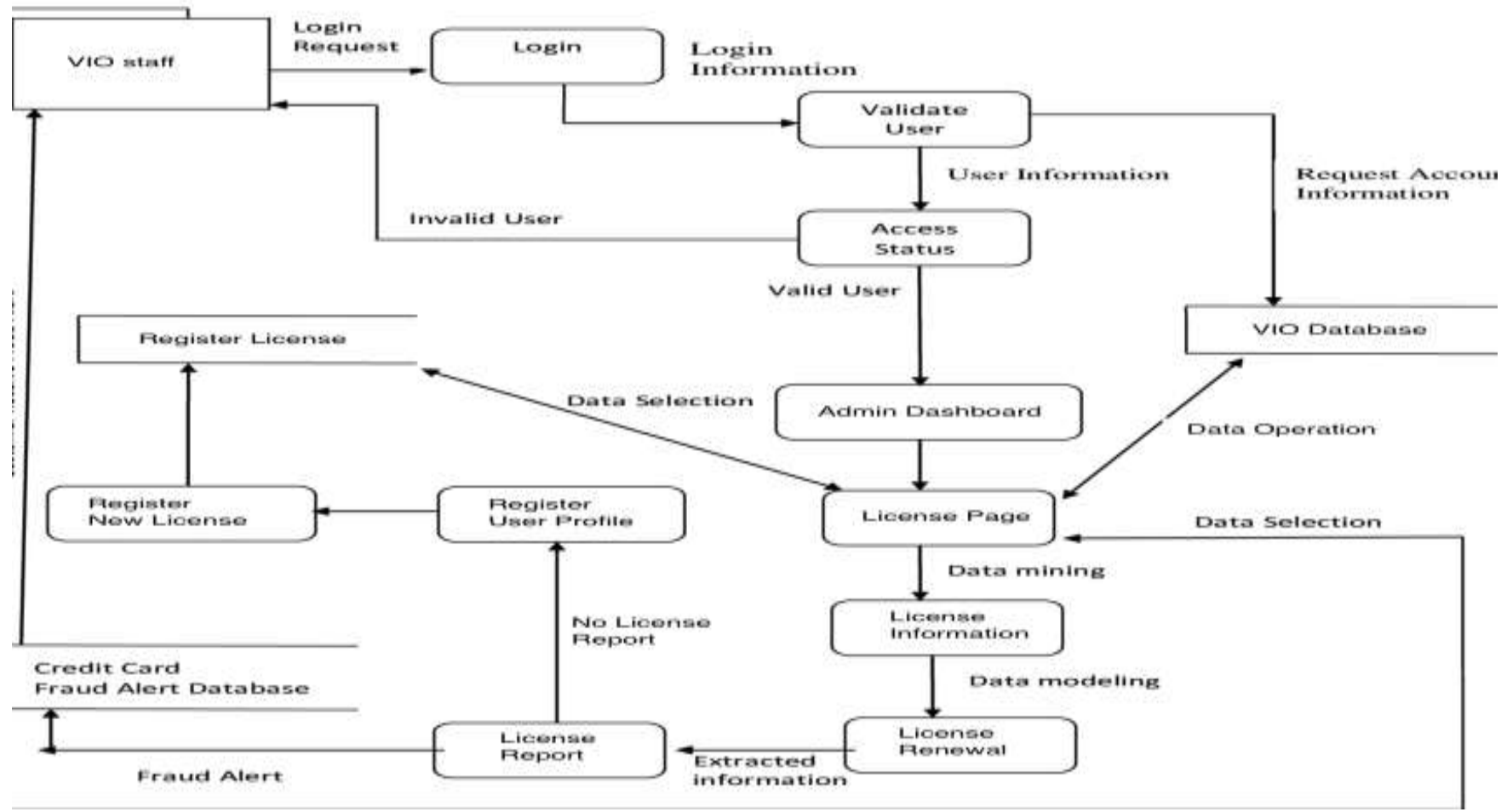

Figure 3.1: Existing system Architecture

\subsubsection{Description of Proposed system}

In the proposed system, a real time online vehicle licensing system that can be used to issue vehicle license automatically by just a pass through the online processing technology, renewal of license, change of ownership and other related matters under vehicle licensing are worked on.

\subsubsection{Advantages of Proposed system}

The proposed system, which is computerized, has so many benefits that will obviate the problems in the current system. The need for this new system cannot be over emphasized as it is aimed at achieving;

(i) Accuracy of Computation: Measures of accuracy will be achieved since the computer system will maintain stability in assigning fees based on assessment and accurate calculation.

(ii) Neatness/Reduced Use of Paper: Computerization gives room for production of a very neat job. Besides, since the vast volume of paper, which is used in keeping/storing information, will no longer be needed, it will help in keeping a very neat office.

(iii) Reduction of Cost: The computerized system will help in reducing cost of operation due to constant production of forms and registers for keeping records as less form will be used.

(iv) Use of Less Space for Record Storage: There will be elimination of much space used in storing records by introducing a computer storage media (disks) which can keep vast volume of information in a less space. 
(v) Speed Optimization: This will eliminate the problems of time wasting in registering records, checking from one line to the next as well as preparing a revenue report which is faster than using manual process to do it.

(vi) Quick Retrieval of Information: There will be fast retrieval of information, which has advantage over the manual system that enables the user to retrieve information faster most especially as it concerns the vehicle owner by making use of his/her vehicle registration number to call up their information than in manual system where one searches for information record line after the other.

(vii) Less tedious and fraudulent free

(viii) Reliability: reliability of records is increases

(ix) Effectiveness and efficiency by reducing work intensity

(x) Ease of update and maintenance of operation

(xi) Consistency of data

\subsection{Design and implementation Methodology}

The implementation methodology used in the proposed system is parallel as a result of the fact that parallel methods support the use of the proposed system side by side with the existing system in order to test for the system efficiency. Top down approach is used in the design because it allows the analysis of the system to be carried out one after the other.

In this stage, the first goal will be decided by task analysis. Next, the prototype of the system will be analyzed. Then test will be made on its usability and design with some design theories. Thus the prototype will be correspondingly looked at. Then a more complete prototype will be tested by potential users to collect feedbacks. Finally, the system will be finalized with the amendment on some problems of the user interface.

\subsubsection{Software Requirements}

Operating system: Windows 8 is used as the operating system as it is stable and supports many features and is user friendly

Database: Mysql is used as database as it easy to maintain and retrieve records by simple queries which are in English language which are easy to understand and easy to write. Besides, it is a free database management system.

Development tools and Programming language- HTML is used to develop webpages with cascading style sheet, java script for styling work and hypertext pre-processor (PHP) for sever side scripting.

Software support includes:

1. A windows 8 operating system.

2. Macromedia Dreamweaver.

3. WAMP server.

4. My SQL database.

5. Internet access as well as anti-virus software which prevents the system from being infected by virus.

\subsubsection{Hardware Requirements}

- Computer.

- Intel core i5 2nd generation is used as a processor because it is fast and it is very reliable and we can as well run our pc for long time with the Intel core i5. By using this processor we can keep on developing our project without any worries.

- $\quad$ Ram 4 GB is used as it will provide fast reading and writing capabilities and will in turn support in processing. 
International Journal of Advances in Scientific Research and Engineering (ijasre), Vol 5 (11), November-2019

\section{Dataflow Diagrams}

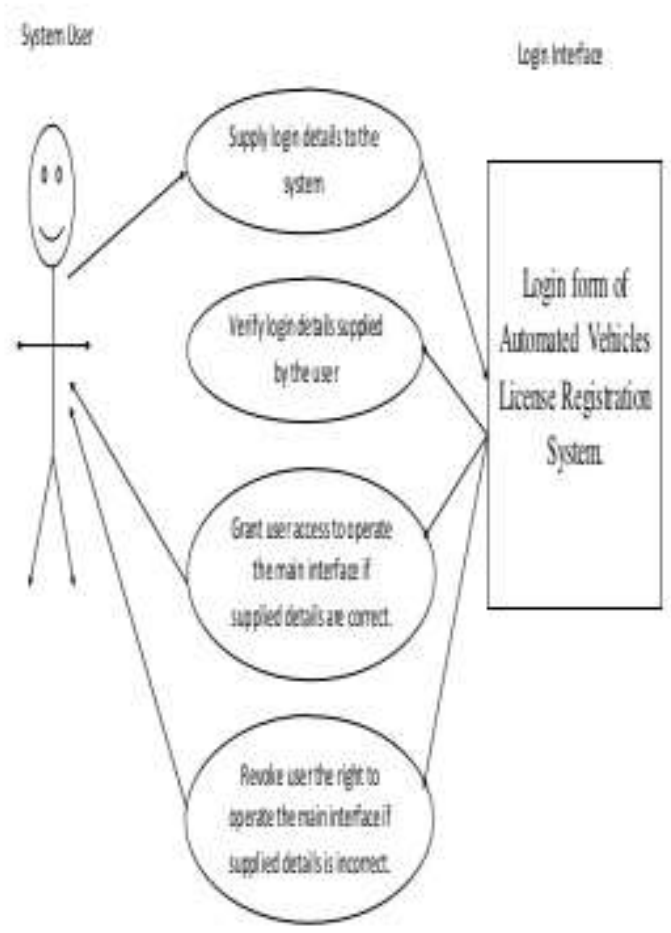

Figure 3.2: UML sequence diagram of computerized online motor vehicle license system: Admin System

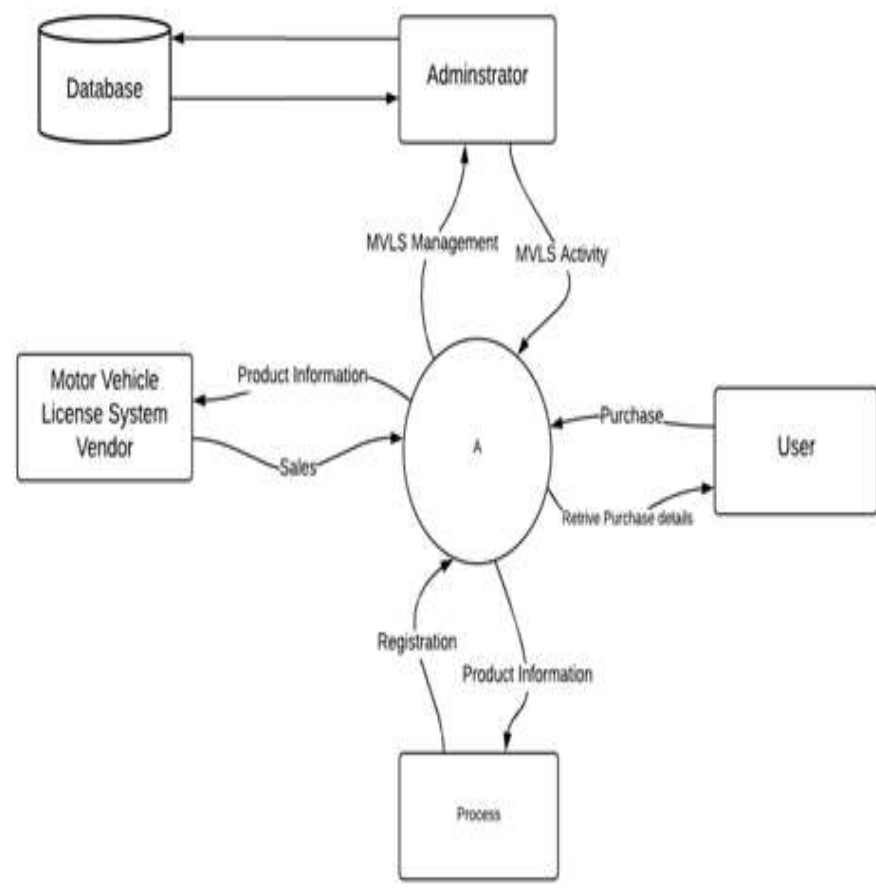

Figure 3.3: New Vehicle Licensing Dataflow Design

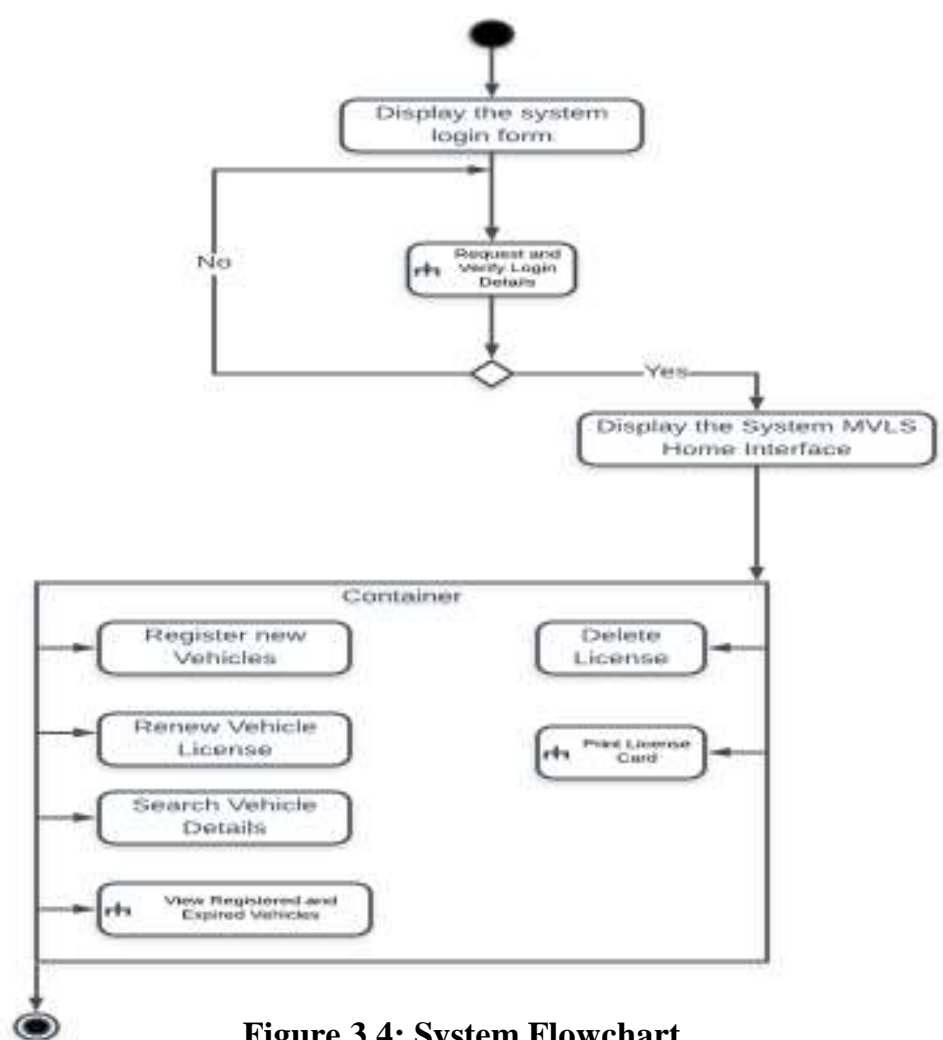

Figure 3.4: System Flowchart 

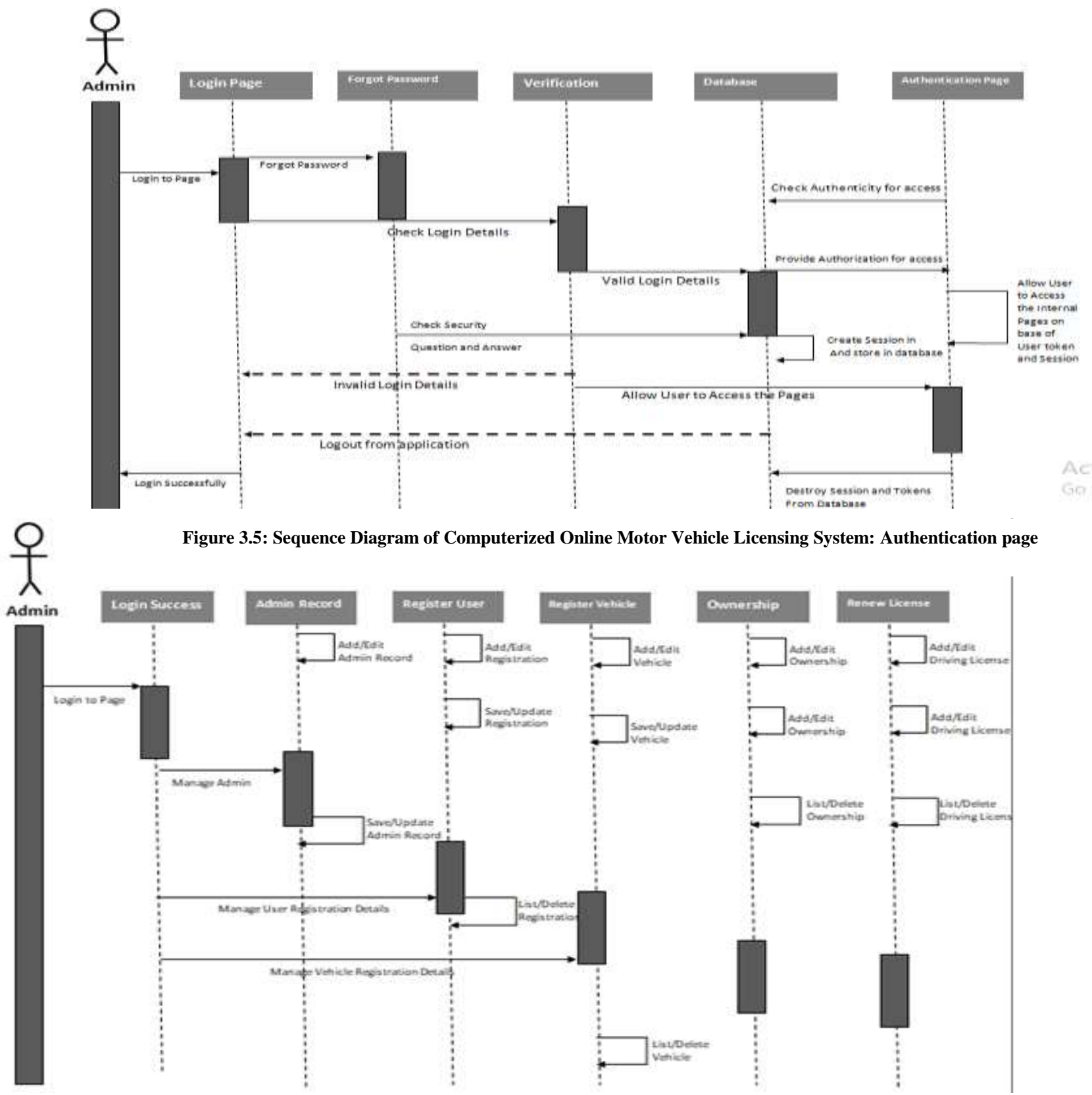

Figure 3.6: Sequence Diagram of Computerized Online Motor Vehicle Licensing System: Dashboard

\section{SUMMARY}

Vehicle License system used to involve manual recording of vehicles information, which ranges from cars to buses and later to truck and heavy duty equipment. Vehicle licensing in Nigeria began over 100 years ago and the records have been essentially manual which in turn has not helped to raise the efficiency of general automotive services in recent years.

The federal government of Nigeria has identified economic development as a major driver for achieving the 2020 socio-economic development. The online vehicle licensing system is a must for any country that wants to be information and communication technology inclined and ready to reduce the vehicle crime rate and corruption in her system.

\section{CONCLUSION}

The understanding of the problems that are very peculiar to vehicle license system was presented in Chapter One and Three of this project; these problems include ineffective, time consuming, tedious, inaccurate, inconsistent, etc. processes which vary from system compatibility to machine dependencies. However big a software research is, these problems and more are likely what they face, and the bigger the software project the more probable it is that they face these problems. 


\section{RECOMMENDATION}

One thing must be researched in the computerization of vehicle license system with the mind of perfecting it and making it more useful in the real sense of things is the security of information handling software. The security of vehicle license system is very crucial considering the prevention of vehicle crime and similar vices so it is worth further researching.

Therefore, it's highly recommended that motor licensing office Abuja, Nigeria should set up a computer based online system with access control to prevent irregularities in its functions.

\section{REFERENCES}

[1] Ikechukwu, D.N. (2015). Nigeria and Traffic Regulations. Ibadan: Africana FEB publishers Ltd.

[2] Balogun, S.A (2016). Road Safety Practice in Nigeria. Nigeria: Resources Nig Ltd. pp. 86-89.

[3] Ayeni, A. J. (2008). A Graph Theoretic Analysis of Intra-Urban Road Network in Ilorin, Nigeria. Research for Development. $17,1 \& 2 ; 18$, Vol. $1 \& 2$; page $221-240$.

[4] Oyesiku, O. O. (2012). From Womb to Tomb. 24th Inaugural Lecture at Olabisi Onabanjo University. Ago-Iwoye: Olabisi Onabanjo University Press.

[5] Ogunsanya, A. O. and Adeniji, S. A. (2015), "Sustaining Urban Public Transport in Nigeria: Critical issues and Remedies" in Freeman and Jamet (eds.) Urban Transport Policy. Balkema, Rotterdam, pp. 775-781.

[6] Filani, M.O. (2012) The Changing Face of Lagos: From Vision to Reform and Transformation. Cities Alliance publishing press, Brussels.

[7] Oyeyemi, B.O. (2013). Stands in Road Traffic Administration Ibadan: Clemeve Media Konsult.

[8] Emmanuel, J.O. (2010). Computer for Everyone. India: Lone and Vikas Publishing House.

[9] Roman, R.; Zhou, J.; Lopez, J. (2013) On the features and challenges of security and privacy in distributed internet of things. Computer Networking, Vol. 57, page 2266-2279

[10] Sicari, S.; Rizzardi, A.; Grieco, L.; Coen-Porisini, (2015). A. Security, privacy and trust in Internet of Things: The road ahead. Computer Networking, Vol. 76, page 146-164.

[11] Sandhu, R.S.; Coyne, E.J.; Feinstein, H.L.; Youman, C.E. (2016). Role-base access control models. Computer, Vol. 29, page $38-47$.

[12] Yuan, E. and Tong, J. (2015). Attributed based access control (ABAC) for web services. In Proceedings of the IEEE International Conference on Web Service, Orlando, FL, USA.

[13] Zhu, Y.; Huang, D.; Hu, C.J.; Wang, X. (2015) From RBAC to ABAC: Constructing flexible data access control for cloud storage services. IEEE Transport Service Computer Vol. 8, page 601-616.

[14] Hardt M, Ligett K, McSherry F, (2012), “A simple and practical algorithm for differentially private data release” NIPS Conference, USA, page 2348-2356.

[15] Peter, B.K and Moses, S.C (2003). Using Information Technology. Complete Edition, (Pg 65-79). New-York: Mc-Graw Hill. 